\title{
Diversité des productions animales et des systèmes d'élevage en Europe. Impacts induits sur les stratégies d'approvisionnement en protéines, éléments de réflexion...
}

\author{
Katell CRÉPON \\ UNIP/ONIDOL - Service technique \\ 12, avenue George V 75008 Paris (France) \\ Tél. $+33(0) 140694996$ \\ Fax $+33(0) 147235872$ \\ $<$.crepon@prolea.com>
}

\begin{abstract}
Current EU self-sufficiency in plant proteins is around 25\% only. Whereas in the past decades the EU has increased its production in plant proteins by 230\% (between 1973 and 2003), the need in protein for feed has increased by $170 \%$ in the same time. The EU has never been self-sufficient, despite strong effort to encourage protein crops. But inside the EU, self-sufficiency in protein of the different Member States cover a large range, from $4 \%$ (the Netherlands) to $46 \%$ (France). This is due to the diversity of crop production possibilities all over the $E U$ but also to the diversity of animal production and animal breeding systems.

Self-sufficiency level is the results of supply in protein crops and demand in protein raw materials. The demand can be influenced by the type of animals fed, the breeding system, and especially the breeding duration, the energy raw materials available... This article aims at examining some factors that could influence self-sufficiency in plant proteins in the $\mathrm{EU}$.
\end{abstract}

Key words: plant proteins, animal feed, self-sufficiency, animal production, breeding systems, EU

1992, le développement de cultures riches en protéines (protéagineux, oléagineux), le taux de couverture en protéines de l'UE n'a jamais excédé $38 \%$ (figure 1). Le développement ininterrompu des productions animales, l'abandon des politiques agricoles en faveur des protéagineux et oléagineux, la suppression
L'Union européenne importe plus des trois quarts de ses besoins en protéines pour approvisionner ses élevages. Le constat n'est pas nouveau: depuis l'avènement des systèmes d'élevage industriels, l'Europe est structurellement déficitaire en protéines. En dépit d'une politique volontariste qui a favorisé, jusqu'en des farines de viandes et d'os des matières premières disponibles pour I'alimentation animale a conduit à une aggravation du déficit européen depuis 1992. En 2004, le déficit de I'UE est revenu à son niveau de 1980.

\section{Déficit en protéines : la diversité européenne}

Mais en matière d'agriculture, l'Europe est diverse. Derrière ce déficit global européen se cache une grande diversité de situations. Ainsi, les Pays-Bas, qui ne disposent que de $1 \%$ de la SAU européenne mais produisent $9 \%$ des aliments composés de I'UE, ont depuis longtemps, par nécessité, fait le choix de s'approvisionner sur le marché mondial et importent $96 \%$ de leurs besoins en protéines végétales. À l'opposé, la France, qui dispose de la plus grande SAU européenne et produit $18 \%$ des aliments composés de l'UE, n'importe « que » $54 \%$ des protéines nécessaires à ses élevages. Toutes les situations intermédiaires existent : le déficit espagnol est de $80 \%$, celui de l'Allemagne de $70 \%$ (figure 2).

Autre constat : I'utilisation de tourteaux de soja dans les formules européennes est variable selon les pays. Le niveau moyen d'incorporation de tourteaux de soja dans les aliments composés en Europe, estimé par le rapport entre la consommation apparente de tourteaux de soja et la production d'aliments com- 


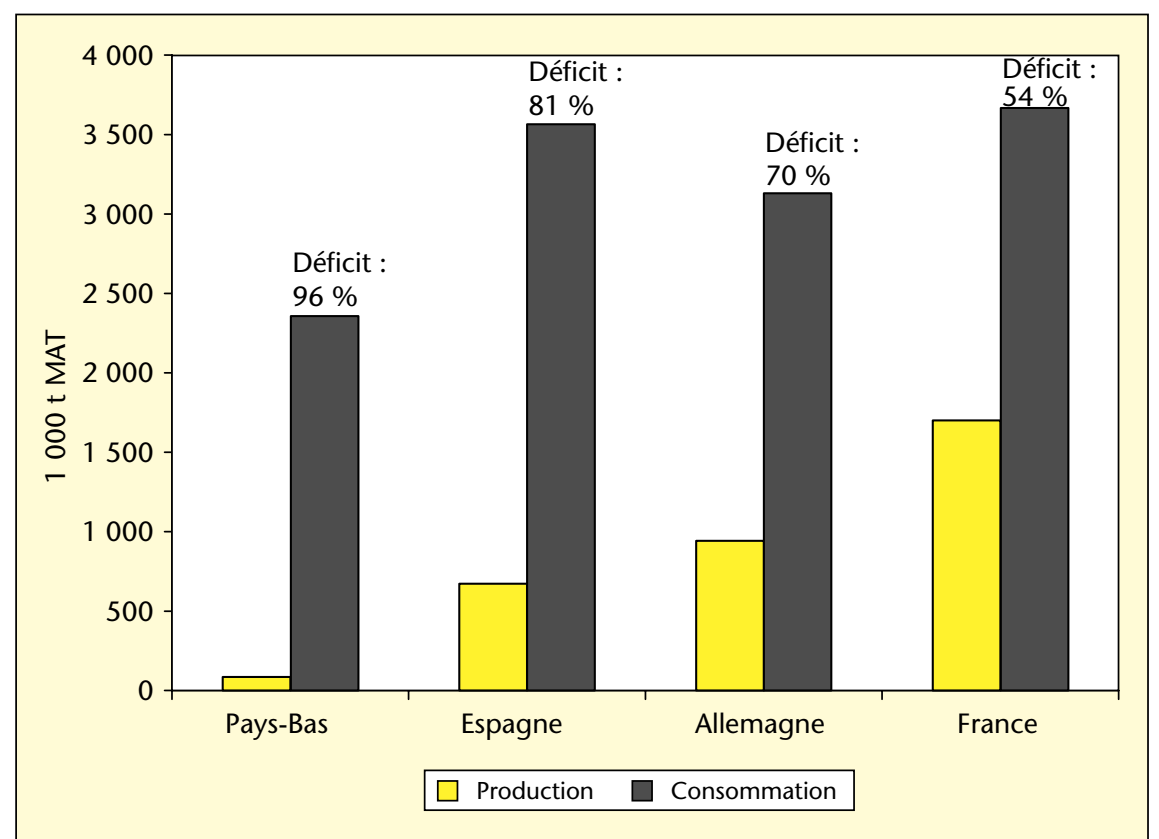

Figure 2. Déficit en protéines de quelques pays de I'UE (2003). Source : UNIP

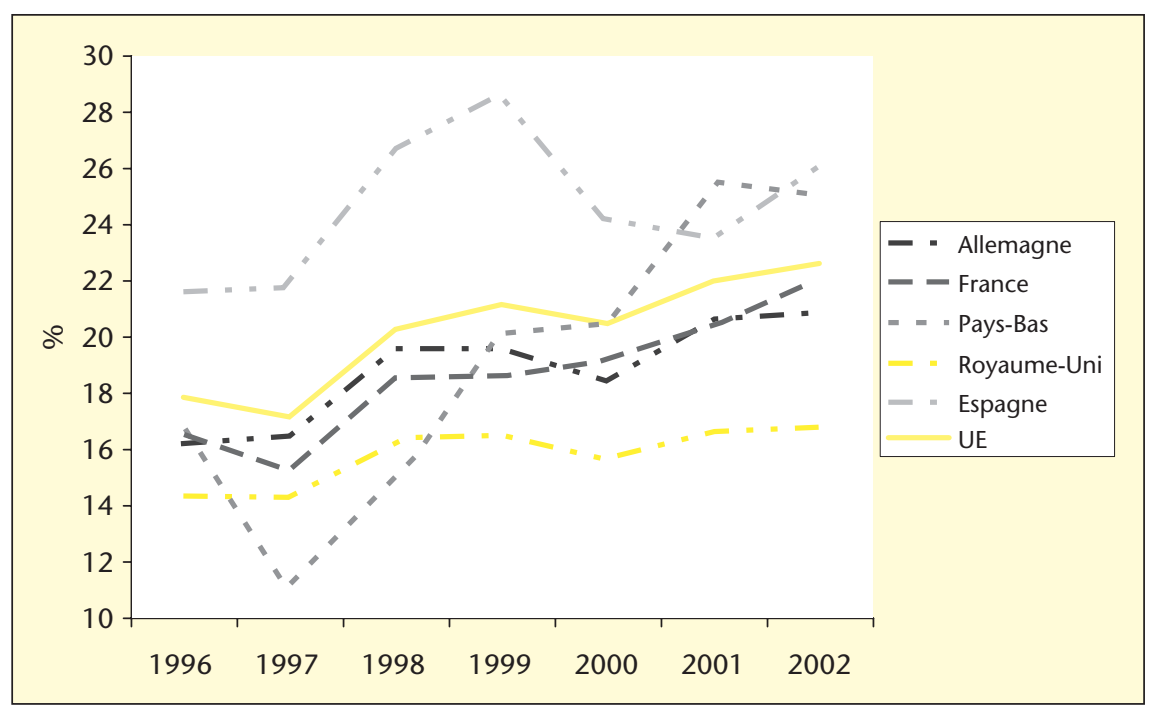

Figure 3. Taux d'incorporation moyen de tourteaux de soja dans les aliments composés en Europe. Source : Eurostat

posés, varie de $17 \%$ pour la Belgique ou le Royaume-Uni à $26 \%$ pour le Danemark, les Pays-Bas ou l'Espagne ${ }^{1}$ (figure 3). Les raisons $d^{\prime}$ un recours accru au soja sont bien connues [1]. Certaines sont d'ordre technique : rations de plus en plus denses en protéines, utilisation

\footnotetext{
${ }^{1}$ En toute rigueur, on devrait également considérer la production d'aliments à la ferme dans ce calcul. Cela n'étant pas le cas, l'incorporation de tourteaux de soja peut être légèrement surévaluée dans les pays où la fabrication d'aliment à la ferme est courante (Allemagne, France, Danemark).
}

les principaux producteurs de viande (Allemagne, Espagne, Royaume-Uni, Belgique, PaysBas, Danemark et République tchèque) [8]. II s'agit d'une étude préliminaire à la construction de modèles de simulation de l'approvisionnement en matières premières des fabricants d'aliments du bétail (FAB). Un des enseignements que l'on peut tirer de cette première étude est que sous une apparente homogénéité, ces secteurs présentent une grande diversité dans les volumes et la nature des productions mais aussi dans les structures et les systèmes d'élevage, les liens avec la production végétale, les contraintes réglementaires... Autant de facteurs qui influent sur les stratégies d'approvisionnement des FAB et des éleveurs, et $a$ fortiori sur le déficit en protéines de ces filières. Nous nous proposons d'en aborder quelques-unes dans cet article. Notre objet n'est pas ici une analyse exhaustive des facteurs expliquant le déficit protéique européen, mais de donner au lecteur quelques clés pour aborder ce problème complexe qu'est l'approvisionnement en protéines de l'Europe.

\section{Volume et nature des productions d'aliments pour animaux en Europe}

Une manière simple d'appréhender les productions animales est d'étudier la production d'aliments destinés aux animaux. La production d'aliments composés dans I'Union européenne était en 2003 de 141 millions de tonnes, stable depuis plusieurs années. Parmi les principaux pays producteurs d'aliments composés, seules I'Allemagne et I'Espagne continuent d'afficher une certaine croissance, les autres pays étant en stagnation ou en régression. La France reste en 2003 le premier producteur d'aliments composés $(22,6 \mathrm{Mt})$ devant l'Allemagne (20 Mt) et I'Espagne (19,4 Mt), mais elle a connu deux années consécutives de baisse de sa production, essentiellement en aliment volaille.

Les aliments produits dans I'Union européenne sont, en légère majorité, des aliments destinés aux porcs (34 \%). Quelques pays font figure d'exception et produisent majoritairement de I'aliment pour volailles : la France (40\%) et le Royaume-Uni (45\%) ou pour bovins : I'Irlande (56\%) et la Suède (51\%).

La nature de I'aliment produit est particulièrement importante dans une problématique de dépendance protéique car l'on sait que les solutions techniques de remplacement du tourteau de soja par d'autres sources de protéines sont peu nombreuses dans les aliments volailles, le tourteau de soja offrant une excellente résistance à une augmentation de son prix. Le caractère « indispensable » du tourteau de soja dans l'alimentation des volailles a 


\section{Encadré 1 \\ Grain legumes IP}

II s'agit d'un projet de recherche soutenu par le Sixième Programme Cadre de Recherche et Développement de I'Union Européenne. II rassemble un large consortium scientifique (60 équipes de 18 pays) autour d'une thématique : améliorer la compétitivité de la culture de légumineuses dans l'agriculture européenne, qui manque de sources de protéines locales pour I'alimentation animale.

Le projet est structuré en 8 modules de travail dont les objectifs sont les suivants :

- identifier les critères de qualité pour une utilisation optimale des légumineuses à graines dans l'alimentation des animaux ;

- montrer l'intérêt des légumineuses dans une agriculture durable ;

- explorer la variation naturelle de composition des graines de légumineuses ;

- identifier les facteurs affectant la composition de la graine ;

- développer des outils de génétique et génomique pour l'amélioration des légumineuses ;

- développer des outils de bio-informatique nécessaires à l'amélioration des légumineuses ;

- coordonner les efforts de recherche en Europe sur les légumineuses à travers ce vaste projet ;

- disséminer les connaissances et organiser les transferts de technologies vers l'industrie.

Notre étude s'intègre dans le deuxième module (agriculture durable). Son objectif est de développer des outils permettant d'appréhender la compétitivité des protéagineux pour I'alimentation animale européenne, d'explorer les voies d'amélioration de cette compétitivité, et d'étudier l'impact sur l'environnement d'un approvisionnement local en protéines des filières européennes de production animale par rapport à une importation massive de tourteaux de soja via des analyses de cycle de vie, réalisées en plusieurs points d'Europe, sur plusieurs produits animaux (viande de porc, viande de volaille, œuf, lait et viande bovine).

Ce projet a démarré en 2004 et s'achève en 2008. II est coordonné par N. Ellis (IIC, Royaume-Uni).

www.eugrainlegumes.org

www.grainlegumes.com

d'ailleurs été considérablement renforcé par I'interdiction des farines de viandes et d'os en alimentation animale.

Par contre, les solutions techniques de complémentation protéique des aliments porcs ou bovins sont plus nombreuses. L'équilibre des régimes peut être assuré par un recours aux protéagineux (pois ou féverole), essentiellement dans les aliments porcs, et aux oléagineux métropolitains (colza et tournesol) pour les aliments bovins et, dans une moindre mesure, porcins. Autrement dit, et en dehors de toute considération sur la disponibilité de sources de protéines locales, il est techniquement plus simple, pour les pays principalement producteurs d'aliment porcs et bovins, de diminuer leur déficit protéique que pour les pays majoritairement producteurs d'aliments volailles.

\section{En production porcine, les solutions techniques pour réduire le déficit protéique existent mais dépendent en partie des surfaces de culture disponibles...}

Dans le secteur de la production porcine, les deux acteurs principaux sont l'Allemagne (26 millions de porcs) et l'Espagne (23 millions de porcs). Ils contribuent ensemble au tiers de la production de I'UE-25. La France, les Pays-Bas et le Danemark, avec des cheptels avoisinant les 12 millions de têtes, participent significativement à la production européenne (respectivement $11 \%, 7 \%$ et $9 \%$ ). Les principales différences entre États membres résident dans la structure des élevages, les contraintes réglementaires, et notamment environnementales qui s'appliquent et la disponibilité des matières premières pour l'alimentation porcine.

La taille des élevages a relativement peu $d^{\prime}$ impact sur leur approvisionnement en protéines, ce qui n'est a priori pas le cas de la surface disponible par élevage (figure 4). En Espagne et aux Pays-Bas, près de la moitié du troupeau reproducteur se trouve sur des exploitations disposant de moins de 10 ha. À I'inverse, en République tchèque, au Danemark et, dans une moindre mesure au Royaume-Uni, la majeure partie du troupeau se situe sur des exploitations ayant une SAU supérieure à 100 ha. Sur ce type d'exploitation, la fabrication de I'aliment sur la ferme est une pratique courante qui permet, lorsque l'assolement est optimisé en fonction des besoins de l'élevage, de produire une partie des protéines nécessaires à I'alimentation des porcins. Une étude réalisée en France, se basant sur des outils d'optimisation des assolements et des formules alimen- taires, a montré que lorsque les assolements sont optimisés en fonction des besoins alimentaires de l'élevage, le pois est presque systématiquement présent dans l'assolement, alors qu'il est rarement introduit lorsque l'optimisation de l'assolement se fait uniquement sur la marge brute des cultures. Par ailleurs, l'étude montre une légère amélioration du résultat d'exploitation lorsque l'assolement est optimisé en fonction des besoins de l'élevage [2]. Le potentiel d'économie de soja résultant de I'utilisation de pois dans les filières porcines est conséquent, comme ont pu le montrer des résultats issus du modèle Prospective Aliments. Dans le contexte de formulation français, le recours au pois permet de réduire de $60 \%$ I'utilisation de soja dans les aliments fabriqués à la ferme pour les porcs [3].

En alimentation porcine, les contraintes environnementales peuvent fortement influencer le choix des matières premières. Lorsque ces contraintes pèsent sur l'azote, l'objectif de la formulation sera de diminuer les excrétions azotées, ce qui s'obtient facilement en baissant la teneur en protéines de la ration. C'est le choix qu'a fait le CORPEN par exemple, en fixant une limite maximale en protéines de $16,5 \%$ en phase de croissance et $15 \%$ en phase de finition. Or, diminuer la teneur maximale en protéines des régimes entraîne une baisse de l'incorporation du pois, du fait notamment de son profil en acides aminés moins adapté que celui d'un tourteau de soja [4]. En terme d'environnement, il existe une certaine uniformisation européenne puisque toutes les réglementations nationales s'appuient sur la Directive Nitrates de I'UE. Cependant, leur application en droit national traduit des sensibilités propres à chaque pays : une forte sensibilité à l'environnement dans les pays du nord de I'UE, avec une orientation sur la maîtrise du phosphore très marquée aux Pays-Bas, une pression sociétale pour l'instant moindre en Espagne... L'impact des différentes politiques environnementales dans I'UE sur le choix des matières premières pour l'alimentation animale reste à creuser.

\section{En production avicole, les solutions pour économiser du soja sont-elles à rechercher dans des systèmes d'élevage alternatifs?}

En 2003, I'Union européenne a produit 9 millions de Tec de viande volailles dont près de $70 \%$ proviennent de poulets de chair. Les $30 \%$ restant se partagent entre la viande de dinde (20\%) et de canard. La France produit à elle seule près du quart de la production euro- 


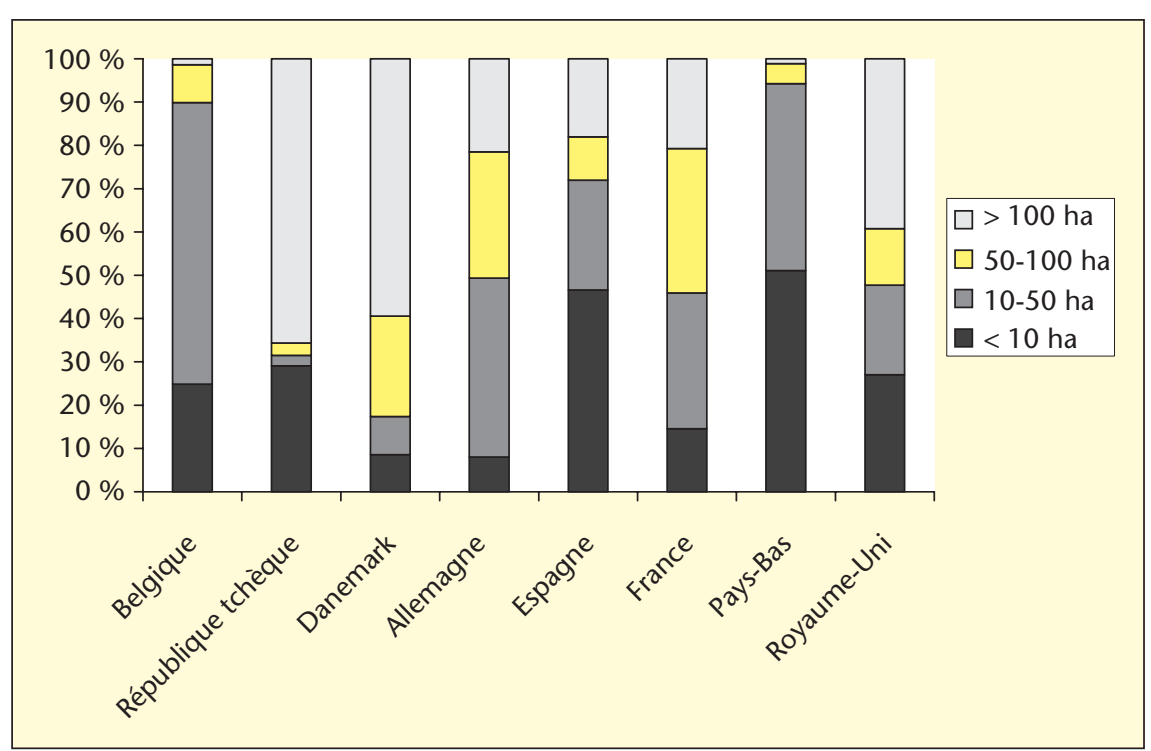

Figure 4. Répartition des truies reproductrices par SAU de l'exploitation. Source : Eurostat

péenne, mais enregistre de fortes baisses de production (près de $10 \%$ entre 2001 et 2003). Le Royaume-Uni, I'Espagne et I'Allemagne connaissent des croissances dynamiques et fournissent respectivement $17 \%$, $15 \%$ et $12 \%$ de la production européenne.

L'âge d'abattage d'un poulet de chair varie en Europe de 35 à 80 jours, en fonction du débouché et de la souche. La teneur en protéines et en énergie des régimes diminue lorsque l'âge d'abattage augmente (tableau 1). Une des conséquences de cette moindre densité nutritionnelle des aliments est que l'incorporation de tourteaux de soja diminue et le prix d'intérêt du pois augmente, son utilisation est ainsi facilitée. La part des poulets abattus à 80 jours (production label) est significative en France (16\%), l'abattage à 56 jours représente aujourd'hui $8 \%$ de la production française mais ce type de production reste marginale dans la plupart des pays de l'UE (moins de $5 \%$ en Grande-Bretagne, deuxième producteur européen de volaille).

Une des solutions techniques pour diminuer la dépendance protéique des filières avicoles pourrait être le développement de productions de volaille à croissance plus lente. Malheureu- sement, les normes de commercialisation européenne stipulent que pour prétendre à l'appellation « fermier-élevé en plein air », les aliments distribués au stade de l'engraissement doivent contenir au moins $70 \%$ de céréales. Dans le même ordre d'idée, la mention "nourri aux céréales » ne peut être apposée que si l'animal a consommé au moins $65 \%$ de céréales pendant la plus grande partie de la période $d^{\prime}$ engraissement. Ce qui laisse peu de place à la complémentation protéique, et renforce la dépendance au tourteau de soja. Une évolution réglementaire pourrait contribuer à la diminution du déficit protéique de ces filières avicoles.

\section{Le troupeau laitier est le principal consommateur de soja}

Bien que dans l'ensemble de I'UE le cheptel laitier tende à régresser, les bovins lait restent les principaux consommateurs de tourteaux de soja en Europe. À ce titre, toute stratégie tendant à réduire la consommation de soja par le troupeau laitier sera particulièrement efficace pour maîtriser le déficit en protéine de l'UE.
Les grands bassins laitiers en Europe sont situés dans le Nord de l'UE : Grand Ouest de la France ( $9 \%$ de la production laitière de l'UE), Centre du Royaume-Uni (7\%), Pays-Bas (10\%), Bavière et Ouest de l'Allemagne (18\%), Ouest du Royaume-Uni (7\%). Toutefois, en regard de la production porcine, la production laitière est assez bien répartie sur l'ensemble du territoire européen.

La production laitière s'est uniformisée en Europe et fait largement appel au couple ensilage de maïs/tourteau de soja et à la race Prim' Holstein, mais les performances de production restent encore assez disparates. Le rendement laitier moyen varie de $5600 \mathrm{~kg} / \mathrm{vache} /$ an (Espagne) à $7900 \mathrm{~kg} / \mathrm{vache} / \mathrm{an}$ (Danemark). Les capacités d'ingestion des animaux étant par contre relativement homogènes, les possibilités de complémentation protéique de la ration de base sont moins nombreuses lorsque le rendement laitier est élevé, seules les matières premières ayant un apport protéique concentré permettent un rationnement équilibré (figure 6). L'extensification de la production laitière peut d'ailleurs être considérée comme une voie d'économie potentielle de tourteaux de soja [3].

Cependant, des solutions techniques existent pour réduire le déficit protéique du secteur laitier sans modifier sa productivité. L'une des plus simples à mettre en œuvre est certainement le remplacement du tourteau de soja par du tourteau de colza. Dans les pays producteurs de tourteau de colza, et en particulier I'Allemagne, I'utilisation de colza en élevage laitier est répandue.

Une autre solution consiste à modifier la ration de base des animaux. En effet, en élevage de ruminants, l'herbe est une source de protéines importante et I'utilisation de l'herbe dans la ration de base accroît les possibilités de complémentation protéique des rations en redonnant de l'intérêt à des matières premières moins concentrées en protéines. Certaines grandes régions laitières en Europe (notamment en Bavière et Basse-Saxe) ont des systèmes de production basés sur l'exploitation de I'herbe. Les modalités d'application de la PAC en Allemagne devraient d'ailleurs renforcer la compétitivité des systèmes herbagers par rap-

Tableau 1. Prix d'intérêt du pois en fonction des contraintes nutritionnelles des formules (et de l'âge d'abattage des animaux).

\begin{tabular}{|lccc|}
\hline & $\begin{array}{c}\text { Finition standard } \\
\text { (abattage 42 jours) }\end{array}$ & $\begin{array}{c}\text { Finition } \\
\text { « intermédiaire * } \\
\text { (abattage 56 jours) }\end{array}$ & $\begin{array}{c}\text { Finition « label " } \\
\text { (abattage 81 jours) }\end{array}$ \\
\hline Min Energie (kcal/kg) & 3200 & 3000 & 2900 \\
Min MAT (\%) & 20 & 17 & 16 \\
Prix d'intérêt du pois & 118,4 & 132,9 & 136,8 \\
$(€ /$ tonne)* & & & \\
\hline
\end{tabular}

* Contexte de prix des matières premières : mars 2005. Source : UNIP, d'après modèle ARIANE. 
port aux systèmes fourragers à base d'ensilage de maïs, la production laitière devant migrer des régions de cultures aux régions de pâturage [5]. Toutefois, ceci ne peut être étendu à toute I'UE, les systèmes fourragers étant en règle générale adaptés aux contraintes de I'environnement: productivité herbagère, mais aussi surface disponible. En effet, pour un même quota laitier, les systèmes herbagers nécessitent $50 \%$ de surface supplémentaire que les systèmes fourragers basés sur le maïs [6]. Les systèmes herbagers en Europe représentent $36 \%$ de la totalité des exploitations laitières européennes, mais ne fournissent que $32 \%$ de la production laitière européenne. En majorité, ce sont des exploitations disposant d'un quota modeste, inférieur à $100000 \mathrm{~kg}$ (pour $40 \%$ $d^{\prime}$ entre elles). Dans ce type de système, moins de $10 \%$ des exploitations ont un quota supérieur à $400000 \mathrm{~kg}$. Ce type d'exploitation laitière est dominant en Suède $(95 \%)$, en Finlande (91\%), au nord du Royaume-Uni (88 \%) et en Irlande (83\%) [7].

À l'inverse, les systèmes fourragers où domine le maïs (part du maïs supérieure à $30 \%$ de la SFP) ne représentent que $11 \%$ des exploitations laitières européennes, mais produisent $17 \%$ du lait en Europe. Ces systèmes sont dominants dans les bassins laitiers de l'ouest de la France, de la Belgique et des Pays-Bas, où la pression foncière est importante.

\section{La nature des matières premières énergétiques et I'utilisation de céréales conditionnent aussi I'utilisation du tourteau de soja}

Parmi les matières premières utilisées en alimentation animale, les matières premières dites énergétiques (céréales, PSC, matières grasses) peuvent représenter jusqu'à $60 \%$ de la formule. Leur nature, et plus particulièrement leur teneur en protéines, a donc une influence importante sur le reste de la formule qui doit apporter le complément protéique. L'utilisation d'une quantité importante de céréales, à faible teneur en protéines, s'accompagne nécessairement de l'emploi d'une source de protéines concentrée et dans bien des cas, le tourteau de soja s'impose.

Suite à la baisse des prix des céréales due aux évolutions de la PAC après 1992, I'utilisation de céréales s'est largement développée en alimentation animale, au détriment des produits de substitution aux céréales comme le manioc, mais aussi de sources de protéines à profil mixte comme le pois. Toutefois, là encore, de profondes différences existent entre pays. Logiquement, les pays producteurs de céréales sont aussi de bons utilisateurs: le Royaume-Uni, I'Allemagne et la France incorporent les céréales entre $40 \%$ et $50 \%$ dans les formules. Certains pays, comme les Pays-Bas ou la Belgique, restent de faibles utilisateurs de céréales, avec des taux d'incorporation moyens dans les formules de l'ordre de $30 \%$, inférieur au taux moyen observé dans I'Union européenne (44 \%). À l'inverse, l'Espagne apparaît comme un gros consommateur de céréales avec des taux d'incorporation dépassant $50 \%$ (figure 5).

Si le blé est la céréale la plus consommée dans I'alimentation animale européenne (45\% en moyenne), l'orge et le maïs sont également bien présents dans les rations. Le maïs est majoritaire dans les aliments composés espagnols. Le manioc a pratiquement disparu des formules, sauf au Pays-Bas ou en Espagne. Ces deux pays, largement déficitaires en céréales, s'approvisionnent sur le marché mondial, notamment en maïs et manioc. Les proportions relatives des différentes céréales ou PSC sont différentes entre chaque pays, et la teneur en protéines du mélange céréalier en est la conséquence (figure 7). Une forte incorporation de mais ou de manioc induit une plus faible teneur en protéines dont la conséquence directe est un recours plus important au soja pour équilibrer la ratio.

Ce rapide tour d'Europe montre que le déficit en protéines de l'UE est la résultante de plusieurs causes, telles que les types de productions animales dominantes (volaille ou porc), les SAU nationales, les structures des élevages et notamment les surfaces disponibles en culture, les contraintes réglementaires (environnement, étiquetage, modalités d'application

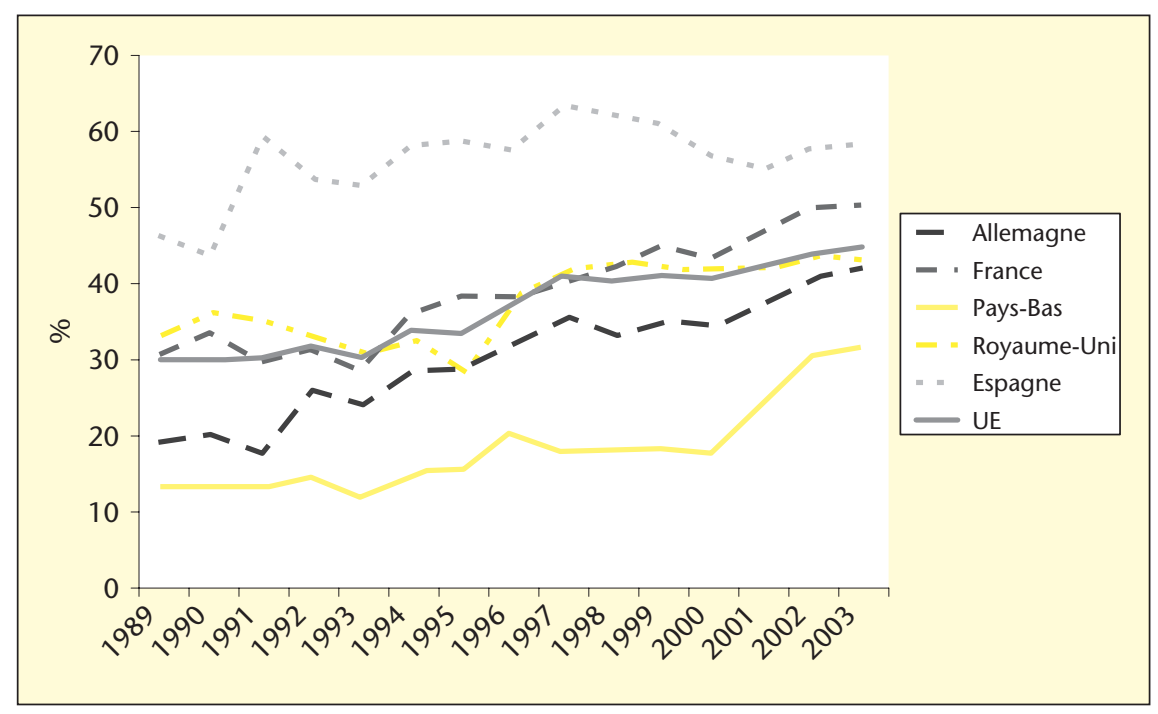

Figure 5. Taux moyen d'incorporation de céréales dans les aliments composés en Europe. Source : FEFAC

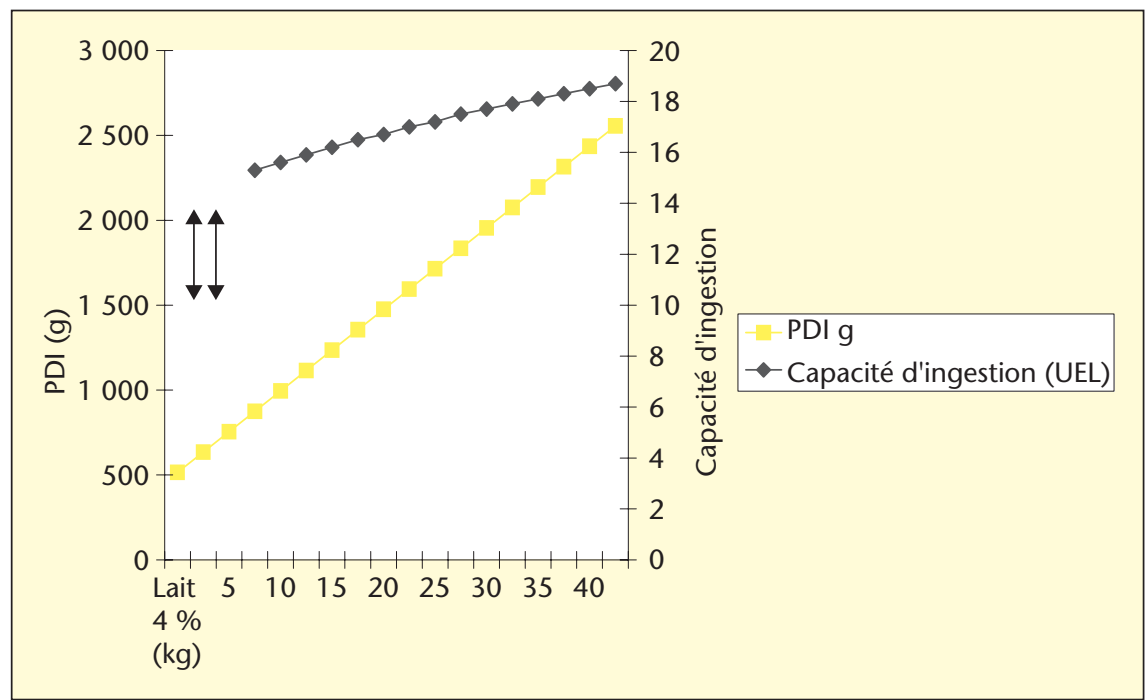

Figure 6. Évolution des capacités d'ingestion et des besoins en PDI en fonction de la production laitière. Source : INRA 


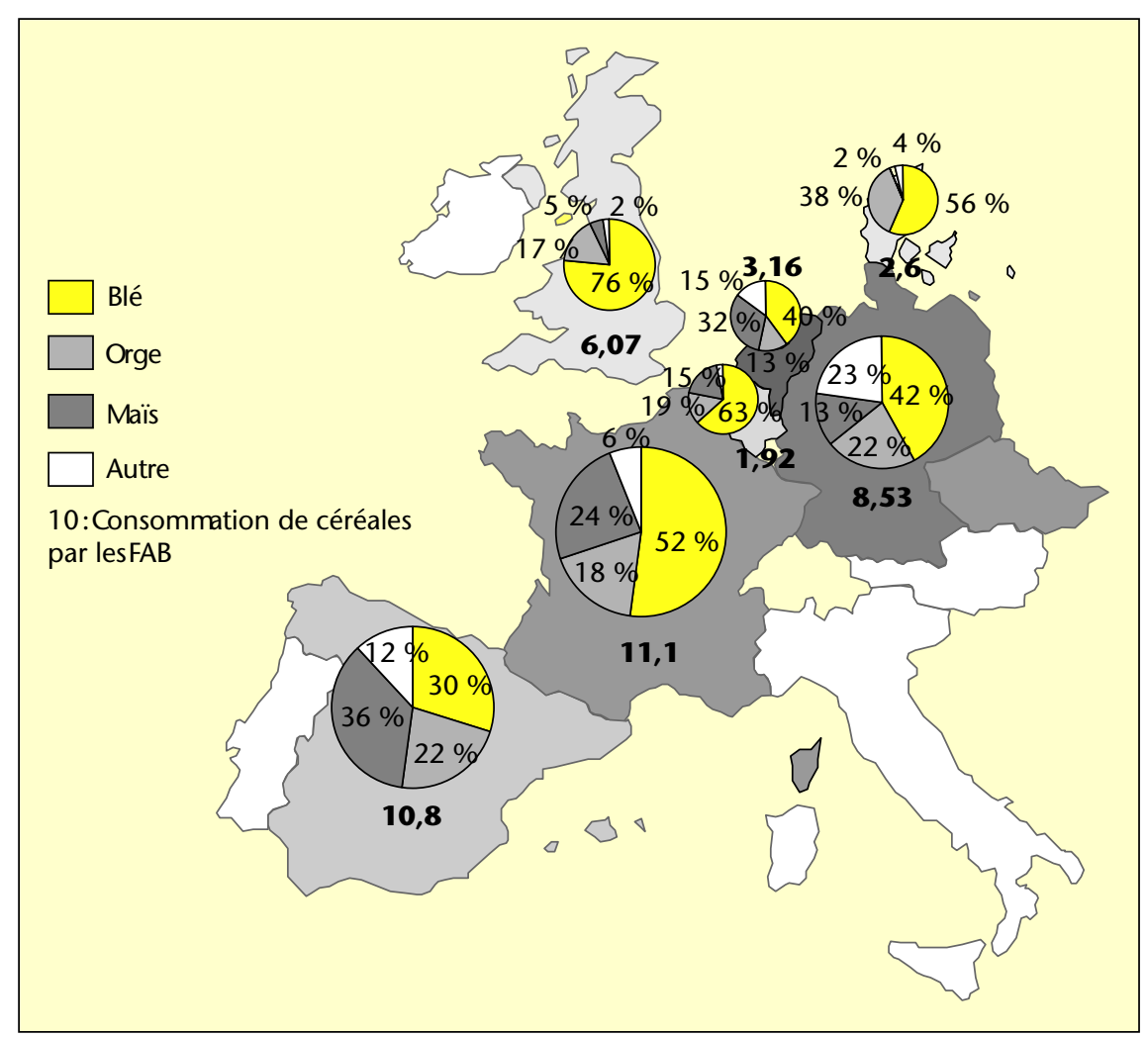

Figure 7. Nature des céréales utilisées dans les aliments pour animaux. Source : Eurostat

de la PAC....). C'est aussi la somme des déficits de chaque pays membres. Or, on l'a vu, certains, comme les Pays-Bas, s'ils maintiennent leur niveau de production animale, ne peuvent prétendre à une amélioration franche de leur déficit en protéines.

Plusieurs pistes doivent être explorées pour réduire le déficit européen :

- augmenter la production de matières premières riches en protéines ;

- diversifier les sources de protéines européennes. Parmi les matières premières candidates à la substitution du tourteau de soja (pois, tour- que pays membre, permettra de retrouver une plus grande autonomie protéique, sous réserve bien sûr que ces solutions techniques garantissent une bonne compétitivité aux productions animales. Les modèles que nous développons au sein du projet européen GLIP (Grain Legumes Integrated Project) devraient nous permettre d'apprécier la compétitivité de ces solutions techniques, de mesurer leur impact sur l'environnement, d'en explorer d'autres et d'apporter, nous l'espérons, quelques éléments de réponses aux nombreuses questions soulevées dans cet article.

\section{RÉFÉRENCES}

1. DELPLANCKE D, LAPIERRE O. 1998. L'approvisionnement européen en protéines : un handicap relatif ? OCL $1998 ; 5$; (4).

2. TEFFENE. Le porc dans les exploitations de grandes cultures. ITP, 1999.

3. PRESSENDA F, LAPIERRE O. Stratégies d'approvisionnement en protéines des fabricants d'aliments composés. CEREOPA, 2002.

4. DOURMAD JY. Evaluation of emissions from pig production, effects of feeding grain legumes. 2004.

5. HOFFMAN H. La réforme de la PAC, les enjeux pour la filière lait de vache en Allemagne. 2004.

teau de colza, tourteau de tournesol...), aucune n'a la polyvalence du soja ;

- adapter les productions animales (durée d'élevage entre autres) ;

- favoriser l'utilisation de céréales plus riches en protéines ;

- dans les milieux favorables à la production herbagère, favoriser les systèmes de production laitière basés sur l'herbe.

\section{Conclusion}

Une combinaison de plusieurs de ces solutions techniques, certainement différente dans cha-
6. RUBIN B. Autonomie alimentaire dans les élevages laitiers des Pays-de-la-Loire, les solutions par territoire et l'intérêt de la filière. 2003.

7. CHATELLIER V, JACQUERIE V. La diversité des exploitations laitières européennes et les effets différenciés de la réforme de la PAC. 2003.

8. CREPON K., COTTRILL B., CECURA L, HUCKO ), MIGUELANEZ M, PRESSENDA F. Animal production sectors in seven European countries - Synthetic report, GLIP, FOOD CT 2004506223. 2005. 